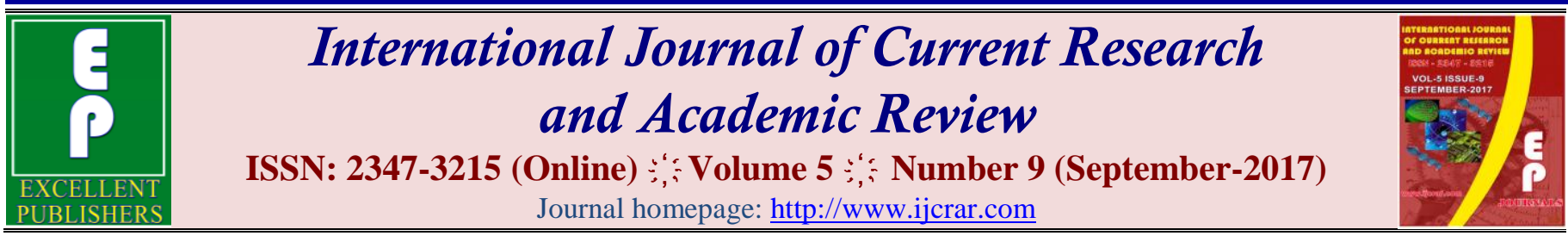

doi: https://doi.org/10.20546/ijcrar.2017.509.004

\title{
Attitude of Teachers towards Continuous Comprehensive Evaluation (CCE)
}

\author{
Sonu Rani* \\ Bharat Vidya Peeth College of Education, Kasandi, Sonepat 131305, Haryana, India
}

*Corresponding author

\begin{abstract}
The present study is an attempt to find out the attitude of teachers towards continuous comprehensive evaluation (CCE). Sample of 200 teachers was taken on the basis of random sampling from Sonepat district. Out of 200 teachers, 100 were taken from Government Schools and 100 were from private schools. For the present study Standardized test named "Teacher's Attitude scale towards CCE" prepared by."Dr Vishal Sood and Dr. (Mrs.) Arti Anand" was used as tool for study. The data were analyzed by employing mean, SD and 't- test. After data analysis the result of the study revealed that attitude of both government and private school in Sonepat district teachers had moderately favorable attitude for the continuous comprehensive evaluation. It also found that 21.5 percent of the teachers had extremely favorable attitude and 36 percent of the teacher had highly favorable while 42.5 had above average favorable attitude toward CCE. This study also found that there was no significance difference in the attitude of private and government school teachers. From this study it was also emerged clearly that there was no significance difference in the attitude of male and female teacher both government and private school in the Sonepat district
\end{abstract}

\section{Article Info}

Accepted: 25 August 2017

Available Online: 20 September 2017

\begin{tabular}{l} 
Keywords \\
\hline Continuous \\
Comprehensive Evaluation, \\
Attitude and Teacher
\end{tabular}

Attitude and Teacher

\section{Introduction}

The main drawback of traditional assessment system in India is that it only develops the ability to answer questions asked in children. It evaluates only the scholastic aspects of the students. The assessment of student achievements may also go wrong due to innumerable reasons. This evolution is based on paper pencil test. Traditional system does not evaluate all the abilities and performance of the students. On the basis of marks obtained by the students in yearly written examination are declared only pass or fail. The biggest problem of this system, students and their parents Due to this system of pass or fail, students most of the times always think that we have to pass this examination either by book crock. So the first thing which comes in to their mind is to mug up the answer and because of this they do not have practical knowledge. Even the teachers do not recognize the inherent talent of students, whereas it is necessary to find out their need and requirements.

Co-scholastic areas are almost ignored in traditional examination system. Taking above point has been felt the need of as a evaluation system which evaluate scholastic and co- scholastic aspect of learns develop. Finally Continuous Comprehensive Evaluation is introduced to overcome the drawbacks of traditional evaluation system. In new evaluation system all the aspects of scholastic \& co-scholastic are considered. NCERT (2003) conducted a study on School Based Evaluation: A 
scheme experimented in primary classes of D.M. School attached to RIE's to seek the answer of the basic questions which are generally raised against the implementation of CCE. The findings of the study revealed that the systematic implementation of the scheme of CCE helping in developing different areas. The implementation of the scheme has helped in identification of indicators and using them for assessing the performance of students both in co-curricular and social personal qualities. It further revealed that the scheme itself ensures the continuous assessment of student's performance, diagnosis and remediation have helped in improving the quality of student's achievement and in scholastic area there is a need for more systematic oral testing.

The continuous \& comprehensive evaluation (CCE) as new evaluation system was initiated based on the recommendations to reform evaluation practices in school education by national curriculum for elementary and secondary education - A framework (1988). The continuous and comprehensive evaluation is a process of determining the extent to which the objectives are achieved. It is not only concerned with the appraisal of achievement, but also with its improvement. Thomas, (2012) found that CCE method is claimed to bring enormous changes from the traditional chalk and talk method of teaching provided it is implemented accurately.

Kumar, 2011 found that Continuous Comprehensive Evaluation was a system of school based evaluation system of a student that covers all aspect of a student development both scholastic and co-scholastic aspect which included life skills. Sharma \& Behal, (2012) studied on emergence of new evaluation system for education $21^{\text {st }}$ century. It was found that Continuous Comprehensive Evaluation facilitates student's effective learning as well as groom all round development of personality with its multiple evaluation tools and technique and corrective measures.

It was most important to make Continuous Comprehensive Evaluation as an integral part of teaching and learning process to promote standard of school education. Singh \& Singh, (2012) studied the role of gender in attitude of school teachers towards Continuous Comprehensive Evaluation. It was found that male and female teacher had favorable attitude towards dimensions formative and summative in Continuous Comprehensive Evaluation, quality control in Continuous Comprehensive Evaluation, grading system in Continuous Comprehensive Evaluation. And male and female teacher did not differ in their attitude towards dimension 'Assessment and record keeping in Continuous Comprehensive Evaluation.

\section{Need of the study}

Assessment that is predominantly of summative nature will not by itself be able to yield a measure of the growth and development of the child. It, at best, certifies the level at achievement only at a given point of time. The paper pencil tests are basically a onetime mode of assessment and to exclusive rely on it to decide about the development at a child is not only unfair but also unscientific. Over emphasis on examinations marks focusing on only scholastic aspects marks children assume that assessment is different from learning, resulting in the 'learn and forget' syndrome. Besides unhealthy competition, the over emphasis on summative assessment system also produces enormous stress and anxiety among the learners. It is this that has led to the emergence of the concept of continuous and comprehensive school based evaluation.

The issue of grading system has been discussed and debated up teen number of times in the national conference of the chairpersons of school education (Sing 2010). Since the concept of CCE is new in India, there is a wide scope to explore this area.

Implementing CCE is a huge task as it involves changing the mind set of teacher. The success of this evaluation system depends upon the active participation of the teacher, where as teacher participation depends upon their attitude towards CCE. Positive attitude can makes the teaching task very easier, satisfying professional and productive, but negative attitude of the teacher makes teaching learning process very harder and productive less.

So this research is a small attempt to find out the teacher's attitude towards continuous comprehensive evaluation. So the knowledge of the teacher's attitude will be helpful for the true implementation and success of continuous comprehensive evaluation system.

\section{Statement of the problem}

In the light of above justification the investigator had planned to conduct the study entitled, "Attitude of Teachers towards Continuous Comprehensive Evaluation." 


\section{Objectives}

The objectives of the study are following:

To study the attitude of government teachers towards CCE.

To study the attitude of private school teachers towards CCE.

To compare the attitude of government and private school teachers towards CCE.

To compare the attitude of male and female government school teachers towards CCE.

To compare the attitude of male and female private school teachers towards CCE.

\section{Hypotheses}

Following hypotheses were framed on the basis of review of related literature:

There is no significant difference between the attitude of government and private school teachers towards CCE.

There is no significant difference between the attitude of male and female government school teachers towards CCE.

There is no significant difference between the attitude of male and female private school teachers towards CCE.

\section{Materials and Methods}

Descriptive research is describing, recording and interpreting the conditions that exist. It involves comparison or contrast and attempt to discover the relationship between the manipulated variables. As the present study was undertaken to compare the Environment Awareness of graduates studied environmental education as compulsory subject with those who have not studied it as compulsory subject, so descriptive method was used.

\section{Sample}

Sample of 200 teachers was taken on the basis of random sampling from Sonepat district. Out of 200 teachers, 100 were taken from Government Schools and 100 were from private schools.
Tool

The selection of suitable instrument or tool is of vital importance for the collection of data in any research work. For the present study Standardized test named “Teacher's Attitude scale towards CCE" prepared by."Dr Vishal Sood and Dr. (Mrs.) Arti Anand" was used as tool for study.

\section{Delimitation of the study}

The study was delimited to 200 teachers only.

The study was delimited to 100 Government and 100 private school teachers only.

The study was delimited to Sonepat District only.

\section{Analysis of data}

\section{Objective-1 Attitude of government school teachers towards CCE}

The collected raw data was tabulated in order to present the data in a systematic and orderly manner. Table 4.1 indicated the overall attitude of government school teachers in the Sonepat district towards CCE of the 100 teachers from government school. The measures of the central tendency mean and median distributed 171.87, 174 respectively which show that most of the government school teachers had above average favorable attitude for the Continuous and Comprehensive Evaluation. Standard deviation of the sample was found to be 23.68. The value of Skewness and Kurtosis i.e. -5.6 and 35.6 respectively shows that the data is skewed towards left side and leptokurtic.

\section{Objective 2: Attitude of private school teachers towards CCE}

Table indicated the overall attitude of government school teachers in the Sonepat district towards CCE of the 100 teachers from government school. The measures of the central tendency mean and median distributed 172.88, 173 respectively which show that most of the teachers had above average favorable attitude for the Continuous and Comprehensive Evaluation.

Standard deviation of the sample was found to be 18.4. The value of Skewness and Kurtosis i.e. -6.1 and 51.9 respectively shows that the data is skewed towards left side and leptokurtic. 
Fig. show 21.5 percent at the teachers were having extremely favorable attitude, 36 percent of the teachers in the Sonepat district were highly favorable attitude and 42.5 percent having the above average favorable towards the continuous comprehensive evaluation system of examination.

\section{Interpretation}

Table 3 revealed that the mean score of government school teachers (171.87) is more than mean score of private school teachers (172.88) in the Sonepat district. The $t$-value is 0.3365 and critical value 1.985 . Hence the t-value is less than the critical value. So the null hypothesis that there is no significant difference between the attitude of government and private school teachers towards CCE was retained, there is no significant difference between the attitude of government school teachers and private school teachers.

As can be seen in fig. 2 that mean attitude score towards CCE of private school teachers 172.88 has been found higher than that at government school teachers, which is 171.87 but the difference is very less. It is emerged clearly that both the group i.e government and private school teacher had favorable attitude towards the continuous comprehensive evaluation.

\section{Comparison of the attitude of government school teacher towards CCE on the basis of gender}

The table 4 revealed that the mean score of female teacher (175.48) is more than mean score of male teachers (174.05). The $\mathrm{t}$-value is 0.77 , as the present $\mathrm{t}$ value is less than critical value. Hence the null hypothesis that is there is no significance difference between the both male and female teachers of government school was retained.

It can be seen in fig. 3 that mean attitude score towards CCE of male teacher 174.05 has been found less than that of female teachers that is 175.48. The results revealed that the female teacher of government school in the Sonepat district have more favorable attitude than the male teacher towards the CCE.

\section{Comparison of the attitude of private school teacher toward CCE on the basis of gender}

The table 6 the mean and standard deviation of private male teacher in the Sonepat district is 175.48 whereas it was 170.28 for private female teachers. The t-value for the present study was 1.4175 , as the present t-value is less than the tabled t- value.

Hence the null hypothesis that is there is no significance difference between the both male and female teachers of private school was retained.

It can be seen in fig. 4.4 that mean attitude score towards CCE of male teachers 175.48 has been found more than that of female teacher that is 170.28 .

The result revealed that the male teacher of private school teacher have more favorable attitude than the female teacher toward the CCE.

\section{Findings}

For this purpose a sample of 200 teachers (100 government school teachers and 100 private school teachers) was taken and administrated the scale of attitude towards CCE on the school teachers.

The important findings of the study are given below.

Most of the government school teachers in the Sonepat district had above average favorable attitude for the Continuous and Comprehensive Evaluation.

Most of the private school teachers in the Sonepat district had above average favorable attitude for the Continuous and Comprehensive Evaluation.

Attitude of both government and private school in the Sonepat district teachers towards continuous comprehensive evaluation was found to be moderately favorable the mean attitude of teachers towards CCE was found to be 172.78 .

21.5 percent of the teachers in the Sonepat district had extremely favorable attitude and 36 percent of the teachers had highly favorable while 42.5 percent had above average favorable toward the existing continuous comprehensive evaluation system as a whole the school have moderate attitude towards CCE.

The mean of the attitude towards CCE of government and private school teachers in the Sonepat district was 171.87 and 172.88 respectively. The t value was 0.3364 which was not significant at 0.05 levels. Hence it was concluded that there was no significance difference in the attitude of government and private school teacher towards CCE. 
Table.1 Attitude of government school teachers towards continuous comprehensive evaluation

\begin{tabular}{|l|l|l|l|l|l|l|}
\hline $\mathrm{N}$ & Mean & Median & S.D & S.E & Skewness & Kurtosis \\
\hline 100 & 171.87 & 174 & 23.68 & 2.4 & -5.6 & 35.6 \\
\hline
\end{tabular}

Table.2 Attitude of private school teachers towards continuous comprehensive evaluation

\begin{tabular}{|l|l|l|l|l|l|l|}
\hline $\mathrm{N}$ & Mean & Median & S.D & S.E & Skewness & Kurtosis \\
\hline 100 & 172.88 & 173 & 18.43 & 1.84 & -6.1 & 51.9 \\
\hline
\end{tabular}

Table.3 Comparison the attitude of government and private school teacher towards CCE

\begin{tabular}{|l|l|l|l|l|l|l|l|}
\hline $\begin{array}{l}\text { School } \\
\text { teacher }\end{array}$ & $\mathrm{N}$ & Mean & SD & DF & 't' Value & $\begin{array}{l}\text { Level of } \\
\text { Significance }\end{array}$ & Remark \\
\hline $\begin{array}{l}\text { Govt. } \\
\text { School } \\
\text { Teacher }\end{array}$ & 100 & 171.87 & 23.67 & 198 & 0.336 & 0.05 & $\begin{array}{l}\text { Not } \\
\text { Significance }\end{array}$ \\
\hline $\begin{array}{l}\text { Pvt. School } \\
\text { Teacher }\end{array}$ & 100 & 172.88 & 18.45 & & & & \\
\hline
\end{tabular}

Table.4 Comparison of the attitude of government school teacher towards CCE on the basis of gender

\begin{tabular}{|l|l|l|l|l|l|l|l|l|}
\hline School & Teacher & N & Mean & SD & Df & T-value & $\begin{array}{l}\text { Significance } \\
\text { level }\end{array}$ & Remarks \\
\hline $\begin{array}{l}\text { Government } \\
\text { School }\end{array}$ & Male & 50 & 174.05 & 8.746 & 98 & 0.77 & 0.05 & No \\
Female & 50 & 175.48 & 9.892 & & & & Significance \\
\hline
\end{tabular}

Table.5 Comparison of the attitude of private school teacher toward CCE on the basis of gender

\begin{tabular}{|l|l|l|l|l|l|l|l|l|}
\hline School & Teacher & $\mathbf{N}$ & Mean & SD & Df & T-value & $\begin{array}{l}\text { Significance } \\
\text { level }\end{array}$ & Remarks \\
\hline $\begin{array}{l}\text { Government } \\
\text { School }\end{array}$ & Male & 50 & 175.48 & 9.892 & 98 & 1.4175 & 0.05 & No \\
Female & 50 & 170.28 & 23.96 & & & & Significance \\
\hline
\end{tabular}

Fig.1 Distribution of favorableness of attitude towards continuous comprehensive evaluation

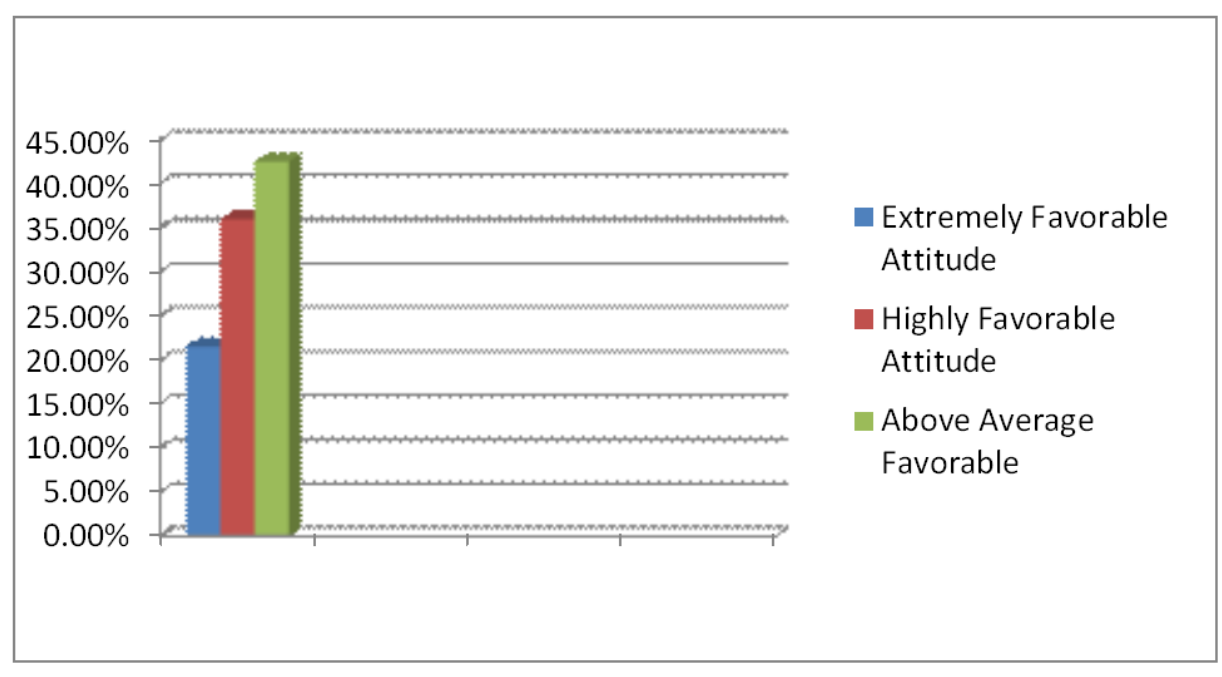


Fig.2 Comparison of the mean and standard deviation of attitude of government and private school teachers towards CCE

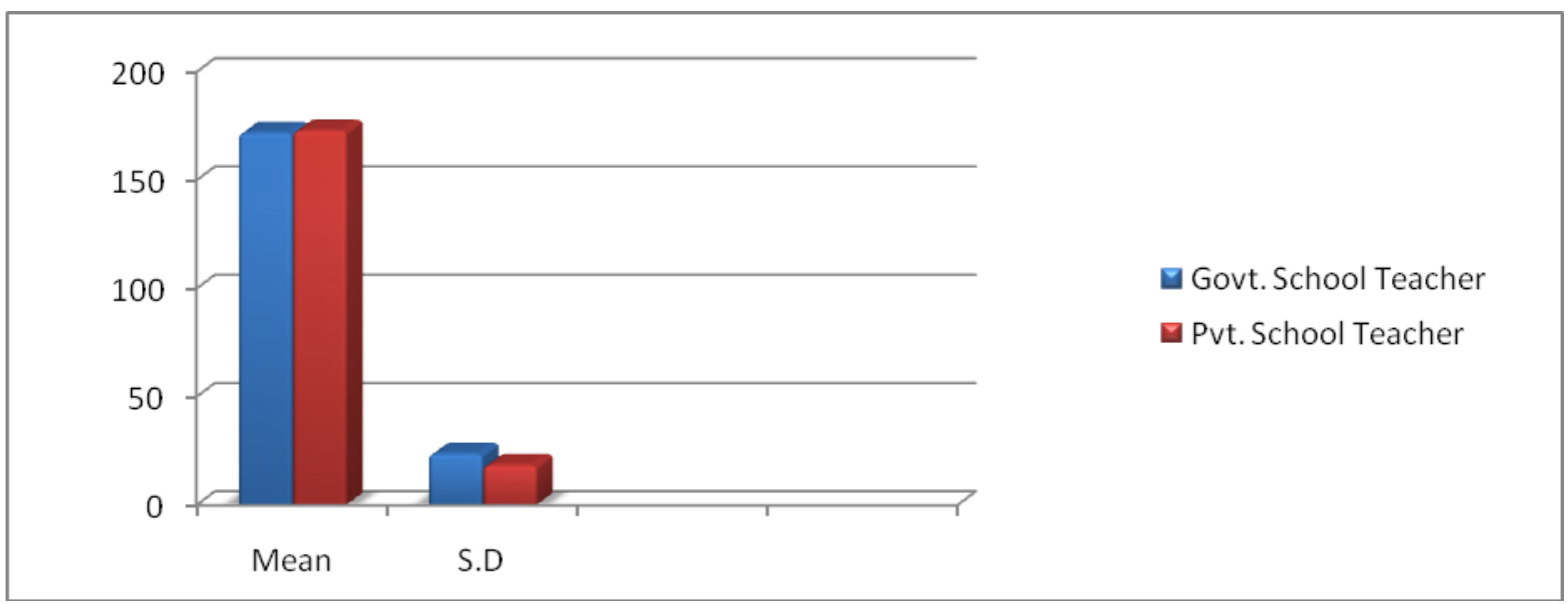

Fig.3 Comparison of the mean and standard deviation of attitude of male and female teacher of government schools towards CCE

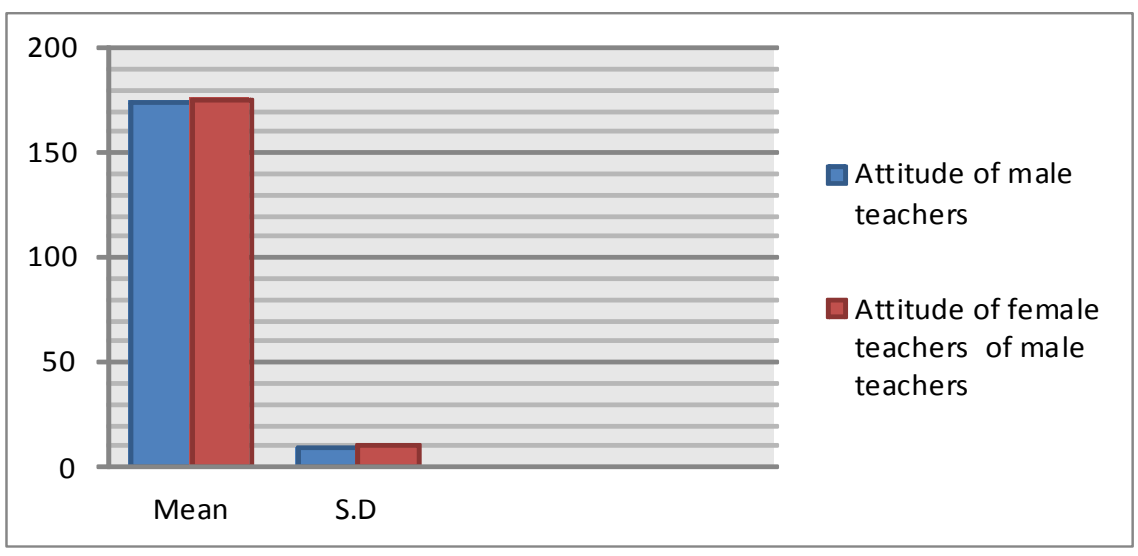

Fig.4 Comparison of the mean and standard deviation of the attitude of male and female teachers of private school towards CCE

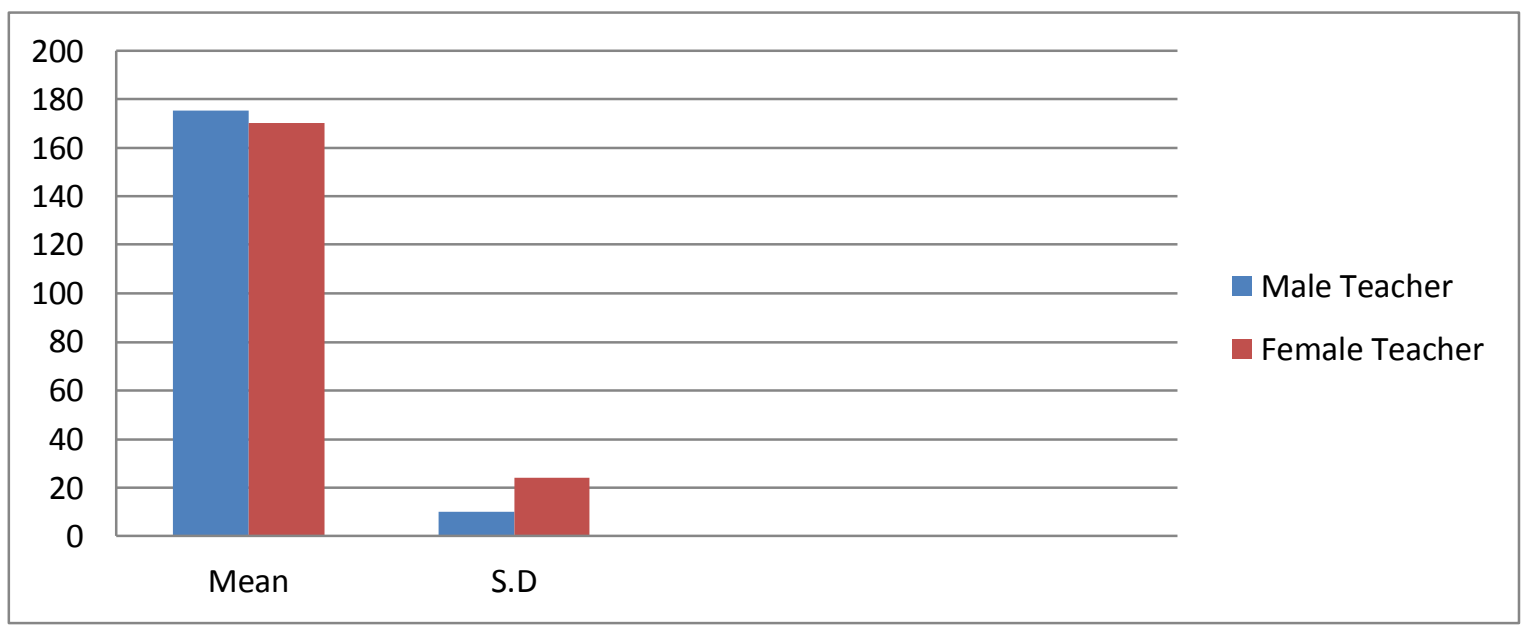


The mean attitude towards CCE of male and female teachers of government school in the Sonepat district was 174.04 and 175.48 respectively; the t-value was 0.77008 which was not significance at 0.05 level. Hence it was concluded that there was no significant difference in the mean attitude towards CCE of male and female teacher of government school.

The mean attitude towards CCE of male and female teachers of private school teacher in the Sonepat district was 175.48 and 170.28 . The t-value was 1.4175 which was not significant at 0.05 level. Hence it was concluded that there is no significant difference in the mean attitude towards $\mathrm{CCE}$ of male and female teacher of private school

Famous psychologist and writer Davit J. Schwartz said that, "How we think shows through in, how we act. Attitude are mirrors of the mind, they reflect thinking." In the same way famous psychologist William James said that the greatest discovery of my generation is that human beings can alter their lives by altering their attitudes. From these two one can easily infer the significance of attitude. Psychologist and educationists through their experiences have realized the importance of attitude of those who are vital part of the education system i.e. teachers, students and administration etc, from the teacher's point of view their attitude towards examination, students, school, or any other component of education. In fact researches have shown that the success and the failure of any system, firm, institution depends upon the attitude of those involved in the system and teachers are the major part of the whole educational process.

The mean attitude score towards CCE of the present study reflected that the attitude of teachers towards continuous comprehensive evaluation is moderately favorable. The present study was found that there was no significant difference in the attitude of private and government school teachers. From this study it was also emerged clearly that there was no significant difference in the mean attitude of male and female teacher both from government and private schools in the Sonepat district. The reason could be that the teachers from different school and gender had realized the importance of the continuous comprehensive evaluation and found this system of evaluation interesting.

The moderately favorable attitude of the teacher emerged through the present study implies that if teaching learning process is continuous, examination than evaluation should also be continuous. And the teacher can best evaluate the student who is constantly in touch with him while the teaching learning process is going on.

From the present study it can be concluded that the attitude of teacher in the Sonepat district towards CCE was found to be favorable. The majority of the teachers were in the favor of continuation of this system of evaluation with certain improvements.

They were of opinion that this system helps both teachers and students time to time in improving themselves, in systematizing and regularizing the studies and students attendance, enhancing the achievement of the students. The functionally streamlined continuous comprehensive evaluation enables the teachers and students to analyze the course content into meaningful segments, prepares the blue print of instructional strategy with build-in evaluation of a formative nature that included a few unit tests, oral tests, field works etc. The formative assessment staggered over the academic session culminated in summative assessment evaluation at the end of the year.

The student community would realize that such a system alleviates their burden of accumulating all that they had acquired over the whole year for three hour regurgitation toward the end will decrease. Over all above the honesty, unbiased attitude and devotion to the duty on the part of the teacher play an important part in the successful implementation and continuation of the continuous comprehensive evaluation. But in a traditional oriented Indian society there is always the tendency on the part of both teachers and students to be attached psychologically to the old traditional examination system. It is natural that any attempt at reforms for the purpose of changing the status quo means resistance from the established order. Finally, no system can be termed to be free from short coming and errors.

As a system the continuous comprehensive evaluation is good but functionally it has its own limitations. But teachers are accepting Continuous and Comprehensive Evaluation whole heartedly both in private as well as government schools and it is a good sign for the Indian education system.

\section{References}

Khothari, R. \& Thomus 2012. A study on implementation of continuous and comprehensive evaluation in upper primary school of Kerala. 
Retrived December 15, 2012 from www.mierjs.in $>$ home $>$ vol 2 No-2.

Kumar, S. \& Behal, A (2012) Emergence of new evaluation system for education in $21^{\text {st }}$ century. Multi-Disciplinary Education global quest coarsely, vol. 1, Issue 1, P.P. 108-113.

Mangal, S.K. (1992) Statistics in Psychology and Education", (Second Reprint), Tata Megraw-Hill Publishing Company Limited, New Delhi.

NCERT (1988) National curriculum for Elementary and secondary Education New Delhi Publication Department NCERT.

NCERT (2004) Evaluation Practices-Across the State. (N.B F23997, Unpublished), New Delhi, India, Kumar S., Gautam S.K.S., Pandit B.L., and Shekhar Chandra K.
Sharma, R.A. (2011): Advanced Statistics in Education and Psychology. Vinay Rakheja Publisher, Pp- 37, 74-83.

Singh, A., Patel, J., \& Desai, R. (2013). Attitude of Student Teachers towards Continuous Comprehensive Evaluation with reference to gender, caste and Habitat. Educational Confab. 2(1): 65 80. [4]

Singh, Richard J. and Others (1986), Washington, DC, "Inside High School Grading Practices, The Northwest Regional Educational Laboratory Program Report", Retrived January 12,2011

Singhal, P. (2012) Continuous and comprehensive evaluation Delhi business review vol. 12, No. 1 from www. Delhibusness review.org IV_13/V/3nid Pdf.

\section{How to cite this article:}

Sonu Rani. 2017. The Attitude of Teachers towards Continuous Comprehensive Evaluation (CCE). Int.J.Curr.Res.Aca.Rev. 5(9), 22-29. doi: https://doi.org/10.20546/ijcrar.2017.509.004 